\title{
Transient Evoked and Distortion Product Otoacoustic Emissions in a Group of Neonates
}

\author{
Giovanna Cesar Silva ${ }^{1}$ Camila Ribas Delecrode ${ }^{1}$ Adriana Tahara Kemp ${ }^{1}$ Fabiana Martins ${ }^{2}$ \\ Ana Claudia Vieira Cardoso ${ }^{1}$ \\ ${ }^{1}$ Department of Speech Language and Hearing Therapy, UNESP- \\ Marilia, Marília, São Paulo, Brazil \\ 2 Department of Fonoaudiologia, Maternity “Gota de Leite," Marília, \\ São Paulo, Brazil

\begin{abstract}
Address for correspondence Giovanna Cesar Silva, Graduate Student, Department of Fonoaudiologia, Universidade Estadual Paulista "Júlio de Mesquita Filho"-Faculdade de Filosofia e Ciências, Av. Hygino Muzzi Filho, 737-Bairro: Mirante, Marília, São Paulo 17.525-000, Brazil
\end{abstract} \\ (e-mail: Ip_gi@hotmail.com; gi.giovannacs@gmail.com).
}

Int Arch Otorhinolaryngol 2015;19:255-258.

\begin{abstract}
Keywords

- audiology

- neonatal screening

- hearing tests

Introduction The most commonly used method in neonatal hearing screening programs is transient evoked otoacoustic emissions in the first stage of the process. There are few studies comparing transient evoked otoacoustic emissions with distortion product, but some authors have investigated the issue.

Objective To correlate the results of transient evoked and distortion product otoacoustic emissions in a Brazilian maternity hospital.

Methods This is a cross-sectional, comparative, and prospective study. The study included 579 newborns, ranging from 6 to 54 days of age, born in a low-risk maternity hospital and assessed for hearing loss. All neonates underwent hearing screening by transient evoked and distortion product otoacoustic emissions. The results were analyzed using the Spearman correlation test to relate the two procedures.

Results The pass index on transient evoked otoacoustic emissions was $95 \%$ and on distortion product otoacoustic emissions was $91 \%$. The comparison of the two procedures showed that $91 \%$ of neonates passed on both procedures, $4.5 \%$ passed only on transient evoked otoacoustic emissions, $0.5 \%$ passed only on distortion product otoacoustic emissions, and $4 \%$ failed on both procedures. The inferential analysis showed a significant strong positive relationship between the two procedures.

Conclusion The failure rate was higher in distortion product otoacoustic emissions when compared with transient evoked; however, there was correlation between the results of the procedures.
\end{abstract}

\section{Introduction}

Language is a primary function of human development, and a prerequisite for its acquisition and development is the anatomical and physiological integrity of the neurologic and auditory system. ${ }^{1}$ Thus, the impact of undetected hearing loss on children's language development and socialization stimulated neonatal hearing screening programs. ${ }^{2}$

Universal newborn hearing screening is a process that aims for early detection of hearing loss and the assessment of hearing in infants with and without risk factors for hearing loss. ${ }^{3}$ In 2010 in Brazil, a law was approved that made the performance of evoked otoacoustic emissions compulsory as a method for newborn hearing screening. ${ }^{4}$ Evoked otoacoustic emissions is fast, noninvasive, easy to apply, and effective in screening programs. ${ }^{5,6}$ Knowledge about the variability of transient evoked otoacoustic emissions (TEOAE) and distortion product otoacoustic emissions (DPOAE) is essential and enhances monitoring the hearing status over time. ${ }^{7}$ received

November 4, 2014

accepted

January 10, 2015

published online

March 2, 2015
DOI http://dx.doi.org/

10.1055/s-0035-1546431. ISSN 1809-9777.
Copyright (c) 2015 by Thieme Publicações License terms Ltda, Rio de Janeiro, Brazil 
The reviewed literature reports that the most commonly used methods in neonatal hearing screening programs are TEOAE and auditory brainstem response, in a second step of the process, when babies fail TEOAE. The combination of both tests was designed to reduce the number of false-negatives, especially in cases of auditory neuropathy/dyssynchrony, and to improve the sensitivity and specificity of universal newborn hearing screening. ${ }^{8-21}$

TEOAE are a major instrument for detection of hearing impairment of cochlear origin, because they allow the study of the mechanical aspects of cochlear function in a noninvasive and objective manner, independent of nerve action potentials. This method does not quantify hearing impairment, but detects its presence. ${ }^{9}$ Thus, the presence of this phenomenon can confirm the integrity of the cochlear mechanism and establishes the functionality of otoacoustic activity of outer hair cells of the cochlea, because TEOAE are present in all individuals whose hearing thresholds are better than 20 - or $30-\mathrm{dB}$ hearing level. ${ }^{10}$

There are reports in the literature that TEOAE and DPOAE are equivalent and effective. ${ }^{22} \mathrm{~A}$ study conducted to compare both methods concluded that TEOAE are faster and assess the medium frequency range, and DPOAE are specific to frequency and evaluate the high frequencies. ${ }^{23}$

The most recommended and most used technique in neonatal hearing screening programs is TEOAE; however, because of the frequency specificity of the DPOAE, researchers have investigated them. ${ }^{24}$

When considering the above, the aim of this study is to compare and correlate TEOAE and DPOAE in neonates of a low-risk maternity hospital.

\section{Methods}

The design used in this study was a comparative, cross-sectional, and prospective. This study was conducted in a low-risk maternity hospital. This is a subproject of the "Hearing Care Program for Children: Hearing Screening for Children from Zero to Three Years Old" research, funded by Fundação de Amparo à Pesquisa do Estado de São Paulo - FAPESP and approved by the Ethics Committee of the Faculty, protocol 0703/2013.

In this program, newborns discharged from the hospital return in about 1 week for the hearing screening. If the newborn failed the test, the retest was scheduled in about 15 days. If newborns did not attend the test or retest, mothers were contacted to schedule a new date.

Inclusion criteria included signing the Term of Free and Informed Consent and the accomplishment of the two types of otoacoustic emissions: transient and distortion product. Subjects were excluded if they attended the maternity hospital for hearing follow-up due to failure in the test and/or the presence of risk indicators for hearing loss. Thus, 579 neonates who attended the neonatal hearing screening program from May to November of 2013, 279 females and 300 males, were included in the study. The age of the newborns ranged from 6 to 54 days (mean 14).

To achieve the objective, the following procedures were employed: anamnesis, TEOAE, and DPOAE. The audiological anamnesis was based on a questionnaire containing identifying data and questions about pregnancy history, delivery, and the newborn, such as birth weight, gender, age, gestational time (preterm or term), type of delivery (vaginally or cesarean section), complications in pregnancy, Apgar score of the baby at 1 and 5 minutes of life, type of feeding, bottle feeding and/or pacifier use, and risk indicators for hearing loss, ${ }^{3}$ plus phototherapy for hyperbilirubinemia.

Evoked otoacoustic emissions were performed with AccuScreen (Madsen - Otometrics, Denmark.), portable equipment used in hearing screening programs. To obtain the responses, the probe was coupled to the external ear of the newborn, preferentially during the neonate's physiological sleep or when he or she was calm and quiet.

We started the screening with DPOAE, followed by TEOAE. TEOAE were evoked by a click stimulus, frequency range from 1.5 to $4.5 \mathrm{kHz}$, and intensity ranged from 45 - to $60-\mathrm{dB}$ hearing level. The minimum stability of the probe was $70 \%$. This equipment analysis shows response peaks; the presence of eight peaks is necessary to consider that the neonate passed the test.

DPOAE were activated by two pure tones, referred to as "primary" tones and abbreviated as $\mathrm{f}_{2}$ (higher frequency) and $f_{1}$ (the lower frequency), that is $f_{2}>f_{1}$. The relation, defined by the ratio expression $f_{2} / f_{1}$, was $1 / 22$.

The intensity levels of stimulus presented was $\mathrm{L}_{1}=60-\mathrm{dB}$ sound pressure level and $\mathrm{L}_{2}=50-\mathrm{dB}$ sound pressure level. The screening used protocol 1 of the equipment that assesses the frequencies of 5, 4, 3,2 kHz. The test was completed when the neonate presented response in three frequencies (pass) or did not respond at two frequencies (refer).

Statistical analysis used the Microsoft (Redmond, Washington, United States) Excel electronic spreadsheet, Microsoft Office 2010 version, to organize the data and the statistical package SPSS (Statistical Package for Social Sciences - SPSS, USA.), version 21.0. A significance level of $5 \%$ (0.05) was adopted. To verify the relationship between variables TEOAE and DPOAE, the Spearman correlation test was used.

\section{Results}

The results of TEOAE and DPOAE showed that the pass index of the TEOAE was higher (95.16\%) than for DPOAEs (91,54\%; -Table 1).

Comparing neonates using the pass/refer index in two procedures unilaterally and bilaterally demonstrated that most of the neonates passed and a minority were referred in both procedures ( - Tables $\mathbf{2}$ and $\mathbf{3}$ ).

There was a significant strong positive correlation both unilaterally and bilaterally between the TEOAE and DPOAE (-Table 4).

\section{Discussion}

The knowledge about the variability of TEOAE and DPOAE is essential and enhances the usefulness in monitoring hearing status over time. ${ }^{7}$ TEOAE are a major instrument for detection of hearing impairment of cochlear origin, because they allow the study of the mechanical aspects of cochlear function in a 
Table 1 TEOAE and DPOAE pass/refer results

\begin{tabular}{|l|l|l|l|}
\hline \multirow{2}{*}{ Test } & \multicolumn{2}{|l|}{ Result } & \multirow{2}{*}{ Total } \\
\cline { 2 - 3 } & Pass & Refer & \\
\hline TEOAE & $551(95.16 \%)$ & $28(4.84 \%)$ & $579(100 \%)$ \\
\hline DPOAE & $530(91.54 \%)$ & $49(8.46 \%)$ & $579(100 \%)$ \\
\hline
\end{tabular}

Abbreviations: DPOAE, distortion product otoacoustic emission; TEOAE, transient evoked otoacoustic emission.

noninvasive and objective manner, independent of nerve

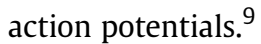

In this study, a comparison between the pass/refer rates of neonates in TEOAE and DPOAE showed that the majority of neonates passed and a minority were referred in both procedures. The pass index for TEOAE was higher than for DPOAE.

In the national literature, the pass index ranged between 85 and $96.78 \%$ using TEOAE as the screening procedure. Some studies have corroborated this finding and others did not. $^{25-28}$ When the DPOAE was used as the screening procedure, authors reported that pass rate ranged from 66.7 to $93.5 \%$, and this variation may be due to the population studied and the protocols used. ${ }^{29}$

In the literature, few studies compared the pass rates using the two procedures in the same population. Unlike the results obtained in this study, researchers used these two procedures, TEOAE and DPOAE, and found a pass rate of $71 \%$ to TEOAE and $97 \%$ to DPOAE. ${ }^{30}$ A possible explanation for a higher pass rate in TEOAE than in DPOAE could be the difficulty in adapting the probe in the acoustic meatus of the patient, which could result in failure to capture the response due to the influence of external and internal noise.
Table 2 joint analysis of pass/refer results in TEOAE and DPOAE

\begin{tabular}{|l|l|l|l|}
\hline \multirow{2}{*}{ TEOAE } & \multicolumn{2}{|l|}{ DPOAE } & \multirow{2}{*}{ Total } \\
\cline { 2 - 3 } & Pass & Refer & \\
\hline Pass & $525(90.67 \%)$ & $26(4.49 \%)$ & $551(95.16 \%)$ \\
\hline Refer & $5(0.87 \%)$ & $23(3.97 \%)$ & $28(4.84 \%)$ \\
\hline Total & $530(91.54 \%)$ & $49(8.46 \%)$ & $579(100 \%)$ \\
\hline
\end{tabular}

Abbreviations: DPOAE, distortion product otoacoustic emission; TEOAE, transient evoked otoacoustic emission.

Although it presents itself as a fast examination in an infant's case, it should be noted that there are difficulties in test performance, for example, stopping the test when the baby is restless. ${ }^{23}$ The literature also reports the influence of noise on DPOAE as the major obstacle to record responses at low frequencies. ${ }^{24,31}$

The correlation of the two types of emissions was positive, strong, and significant. Although few studies compared and correlated these two procedures, the results corroborate the findings of this study. ${ }^{22,23,30,32}$

One study showed a significant correlation between the results of TEOAE and DPOAE and demonstrated the reliability of the two types of otoacoustic emissions in the accomplishment of newborn hearing screening in preterm neonates. ${ }^{30,31,33}$

A comparison of TEOAE and DPOAE in preschool children showed that the signal-to-noise ratio in TEOAE was smaller than in DPOAE, and this difference was significant for low frequencies and not significant for high frequencies. The authors reported that this was the first study to focus on the comparison of the two methods and concluded that both are equivalent and effective and recommended for this population assessment. ${ }^{7,22}$

Table 3 TEOAE and DPOAE pass/refer results considering the ear

\begin{tabular}{|l|l|l|l|l|}
\hline \multirow{2}{*}{ TEOAE } & \multicolumn{2}{|l|}{ DPOAE } & \multicolumn{2}{l|}{} \\
\cline { 2 - 5 } & \multicolumn{2}{|l|}{ RE } & Refer & \multicolumn{2}{l|}{ Pass } & Refer \\
\cline { 2 - 5 } & Pass & & & \\
\hline RE & & $15(2.59 \%)$ & - & - \\
\hline Pass & $548(94.64 \%)$ & $12(2.07 \%)$ & - & - \\
\hline Refer & $4(0.69 \%)$ & & & $12(2.07 \%)$ \\
\hline LE & & - & $547(94.47 \%)$ & $18(3.1 \%)$ \\
\hline Pass & - & - & $2(0.34 \%)$ & \\
\hline Refer & - & - & & \\
\hline
\end{tabular}

Abbreviations: DPOAE, distortion product otoacoustic emission; LE, left ear; RE, right ear; TEOAE, transient evoked otoacoustic emission.

Table 4 Analysis of the correlation of TEOAE and DPOAE

\begin{tabular}{|l|l|l|l|}
\hline Variable correlated & Sample $(\boldsymbol{n})$ & Correlation coefficient $(\boldsymbol{r})$ & Significance $(\boldsymbol{p})$ \\
\hline TEOAE $\times$ DPOAE $($ RE) & 579 & +0.562 & $<0.001^{\mathrm{a}}$ \\
\hline TEOAE $\times$ DPOAE $($ LE) & 579 & +0.711 & $<0.001^{\mathrm{a}}$ \\
\hline TEOAE $\times$ DPOAE (bilateral) & 579 & +0.538 & $<0.001^{\mathrm{a}}$ \\
\hline
\end{tabular}

Abbreviations: DPOAE, distortion product otoacoustic emission; LE, left ear; RE, right ear; TEOAE, transient evoked otoacoustic emission.

${ }^{a}$ Significant. 
The transient otoacoustic emissions are faster and better assess the medium-frequency range, and the distortion products are frequency-specific and better assess high frequencies. $^{23}$

The most recommended and most used technique in neonatal hearing screening programs is the TEOAE; however, due to frequency specificity of DPOAE, researchers are interested in comparing their results with those of TEOAE. ${ }^{24}$

Given the above, the type of otoacoustic emissions has advantages and disadvantages, but the association of both procedures would allow a better sensitivity and specificity of neonatal hearing screening.

\section{Conclusion}

In this study comparing TEOAE and DPOAE, a significant correlation was found between the two procedures, which demonstrates the reliability of the methods employed.

\section{References}

1 Rosseto DdeL, Ribeiro SC, Mendonça MP, Oliveira JA, Reis AC, Dutra SG. Análise das habilidades auditivas de um grupo de indivíduos com história de uso de drogas ilícitas. Braz J Otorhinolaryngol 2009;75(5):685-693

2 Pereira PKS, Azevedo MF, Testa JR. Conductive impairment in newborn who failed the newborn hearing screening. Braz J Otorhinolaryngol 2010;76(3):347-354

3 Year 2007 Position Statement: principles and guidelines forearly hearing detection and intervention programs. American Academy of Pediatrics, Joint Committee on Infant Hearing. 2007;120(4): 898-921

4 BRASIL. Lei n.12.303, de 2 de agosto de 2010. Dispõe sobre a obrigatoriedade de realização do exame demoninado Emissões Otoacústicas Evocadas. Portal da Legislaçãol: Leis Ordinárias. 2010. Available at: http://www.planalto.gov.br/ccivil_03/_Ato2007-2010/ 2010/Lei/L12303.htm

5 Patel H, Feldman M. Canadian Paediatric Society, Community Paediatrics committee. Universal newborn hearing screening. Paediatr Child Health 2011;16(5):301-305

6 Kemp DT. Otoacoustic emissions, their origin in cochlear function, and use. Br Med Bull 2002;63:223-241

7 Keppler H, Dhooge I, Maes L, et al. Transient-evoked and distortion product otoacoustic emissions: a short-term test-retest reliability study. Int J Audiol 2010;49(2):99-109

8 Silva DP, Martins RH. Analysis of transient otoacoustic emissions and brainstem evoked auditory potentials in neonates with hyperbilirubinemia. Braz J Otorhinolaryngol 2009;75(3):381-386

9 Kemp DT, Bray P, Alexander L, Brown AM. Acoustic emission cochleography-practical aspects. Scand Audiol Suppl 1986;25:71-95

10 Côrtes-Andrade IF, Bento DV, Lewis DR. Emissões Otoacústicas Evocadas por Estímulo Transiente: protocolos de Triagem Auditiva Neonatal. Rev CEFAC 2013;15(3):521-527

11 Azevedo MF. Emissões otoacústicas. In: Figueiredo MS, ed. Conhecimentos para entender bem as emissões otoacústicas e BERA. São Paulo, Brazil: Pulso; 2003:35-83

12 Borges CAB, Moreira LMO, Pena GM, Fernandes FR, Borges BCB, Otani BH. Universal neonatal hearing screening. Intl. Arch. Otorhinolaryngol 2006;10:28-34

13 Ilha L, Kasse C, Mesquita Neto O, Almeida CR, Cruz OLM. Ototoxicidade induzida pela cisplatina em cobaias: efeito dose-dependente -avaliação funcional. Acta Otolaryngol 2007;25: 112-118
14 Matas CG. Audiometria de tronco cerebral. In: Carvalho RMM, ed. Fonoaudiologia: informacao para a formacao. Rio de Janeiro, Brazil: Guanabara Koogan; 2003:43-57

15 Benito-Orejas JI, Ramírez B, Morais D, Almaraz A, Fernández-Calvo JL. Comparison of two-step transient evoked otoacoustic emissions (TEOAE) and automated auditory brainstem response (AABR) for universal newborn hearing screening programs. Int J Pediatr Otorhinolaryngol 2008;72(8):1193-1201

16 Simonek MCS, Azevedo MF. Respostas falso-positivas na triagem auditiva neonatal universal: possíveis causas. Rev CEFAC 2011; 13(2):292-298

17 Bubbico L, Bartolucci MA, Broglio D. The newborn hearing screening in Italy. Int J Pediatr Otorhinolaryngol 2005;31:290-292

18 De Capua B, Costantini D, Martufi C, Latini G, Gentile M, De Felice C. Universal neonatal hearing screening: the Siena (Italy) experience on 19,700 newborns. Early Hum Dev 2007;83(9):601-606

19 Lewis DR, Marone SA, Mendes BC, Cruz OL, Nóbrega Md. Multiprofessional committee on auditory health: COMUSA. Braz J Otorhinolaryngol 2010;76(1):121-128

20 Gilbey P, Kraus C, Ghanayim R, Sharabi-Nov A, Bretler S. Universal newborn hearing screening in Zefat, Israel: the first two years. Int J Pediatr Otorhinolaryngol 2013;77(1):97-100

21 Ghirri P, Liumbruno A, Lunardi S, et al. Universal neonatal audiological screening: experience of the University Hospital of Pisa. Ital J Pediatr 2011;37:16

22 Dille M, Glattke TJ, Earl BR. Comparison of transient evoked otoacoustic emissions and distortion product otoacoustic emissions when screening hearing in preschool children in a community setting. Int J Pediatr Otorhinolaryngol 2007;71(11): 1789-1795

23 Xue X, Zhong N. A study on the correlation between distortion product otoacoustic emissions and transient evoked otoacoustic emissions [article in Chinese]. Lin Chuang Er Bi Yan Hou Ke Za Zhi 2003;17(4):198-200

24 Raineri GG, Coube CZV. 2, Costa Filho OA, Alvarenga KF. Emissões otoacústicas evocadas-produto de distorção em neonatos audiologicamente normais. Braz J Otorhinolaryngol (Engl Ed) 2001; 67(5):644-648

25 Rodrigues PAL, Carvalho TSF, Lauris JRP, Schochat E. Results of a newborn hearing screening program in Cuiabá-Mato Grosso, Brazil. Rev Soc Bras Fonoaudiol 2011;16:454-458

26 Françozo MdeF, Fernandes JC, Lima MCMP, Rossi TRF. Improvement of return rates in a neonatal hearing screening program: the contribution of social work. Soc Work Health Care 2007;44(3): 179-190

27 Lima GM, Marba ST, Santos MF. Hearing screening in a neonatal intensive care unit. J Pediatr (Rio J) 2006;82(2):110-114

28 Boscatto SD, Machado MS. Hearing screening of São Vicente de Paulo Hospital: survey data. Rev CEFAC 2013;15:1118-1124

29 Md Daud MK, Sidek D, Abd Rahman N, Mansor S, Zakaria MN. The performance of distortion product otoacoustic emissions and automated auditory brainstem response in the same ear of the babies in neonatal unit. Int J Pediatr Otorhinolaryngol 2012;76(9): 1366-1369

30 Costa JMD, Almeida VF, Oliveira CACP, Sampaio ALL. Transient and distortion product evoked otoacoustic emissions in premature infants. Intl Arch Otorhinolaryngol 2009;13(3):309-316

31 Bonfils P, Avan P, François M, Trotoux J, Narcy P. Distortion-product otoacoustic emissions in neonates: normative data. Acta Otolaryngol 1992;112(5):739-744

32 Lonsbury-Martin BL, Whitehead ML, Martin GK. Clinical applications of otoacoustic emissions. J Speech Hear Res 1991;34(5):964-981

33 Lopes Filho O, Carlos R, Thomé D, Eckley C. Emissões otoacústicas transitórias e produtos de distorção na avaliação de recém-nascidos com poucas horas de vida. Braz J Otorhinolaryngol 1996;62(3): 220-228 